1 Fundação Oswaldo Cruz (Fiocruz), Escola Nacional de Saúde Pública Sergio Arouca (Ensp), Programa de Pós-Graduação Stricto Sensu em Saúde Pública - Rio de Janeiro (RJ), Brasil. Ministério da Saúde, Departamento de Atenção Básica (DAB) - Brasília (DF), Brasil. Associação Brasileira de Saúde Coletiva (Abrasco), GT de Promoção da

Saúde e Desenvolvimento Sustentável - Rio de Janeiro (RJ), Brasil.

fabiofbcarvalho@gmail.com

2 Fundação Oswaldo Cruz (Fiocruz), Escola Nacional de Saúde Pública Sergio Arouca (Ensp), Departamento de Saneamento e Saúde Ambiental (DSSA) - Rio de Janeiro (RJ), Brasil. cohen@ensp.fiocruz.br

3 Universidade de São Paulo (USP), Faculdade de Saúde Pública (FSP) - São Paulo (SP), Brasil. Associação Brasileira de Saúde Coletiva (Abrasco), GT de Promoção da

Saúde e Desenvolvimento Sustentável - Rio de Janeiro (RJ), Brasil. marcoakerman@usp.br

\section{Refletindo sobre o instituído na Promoção da Saúde para problematizar 'dogmas'}

\author{
Reflecting on the established in Health Promotion to problematize \\ 'dogmas'
}

Fabio Fortunato Brasil de Carvalho', Simone Cynamon Cohen², Marco Akerman

RESUMO O ensaio busca problematizar temas importantes para a construção teórico-conceitual da Promoção da Saúde, que é discutida a partir de múltiplas concepções. Por meio de revisão bibliográfica, buscou-se embasamento para a defesa de que a Promoção da Saúde é mais ampla que a prevenção de doenças, mas não pode prescindir dela, além da possibilidade de mudanças comportamentais construídas a partir do empoderamento dos sujeitos e coletividades e da importância da abordagem individual. Conclui-se que a Promoção da Saúde é uma importante forma de produzir saúde, o que inclui as ações cotidianas nos serviços de saúde e no espaço micropolítico da vida.

PALAVRAS-ChAVE Promoção da Saúde. Prevenção de doenças. Autonomia pessoal. Atenção Primária à Saúde.

ABSTRACT The essay seeks to discuss issues that are important to the theoretical and conceptual construction of Health Promotion, which is discussed from multiple views. Through literature review, we sought foundation for the defense that Health Promotion is broader than the prevention of diseases, but cannot do without it, besides the possibility of behavioral changes built from the empowerment of subjects and collectives. We conclude that Health Promotion is an important way to produce health, which includes the daily actions in health services and in the micro-political space of life.

KEYWORDS Health Promotion. Disease prevention. Personal autonomy. Primary Health Care. 


\section{Introdução}

A Promoção da Saúde (PS), além de campo de formulações teóricas, é, sobretudo, um espaço de manifestações práticas na realidade social (VERDI; CAPONI, 2005) e, no Sistema Único de Saúde (SUS), é uma estratégia conceitual e prática para a mudança no modelo de organização dos serviços de saúde.

Argumenta-se neste ensaio que a PS, em sua vertente crítica, contribui para prevenir doenças, buscando superar algumas limitações que esse conceito traz. Para relativizar a dicotomia entre PS e prevenção de doenças, tema estruturante para aquela, propõe-se apresentar seus conceitos apontando algumas formas de como eles são traduzidos em práticas nos serviços de saúde da Atenção Básica (AB).

Denomina-se como o instituído na PS a defesa de que algumas estratégias, a priori, não poderiam ser relacionadas com a vertente crítica, tais como a mudança de comportamento, as estratégias individuais e, ainda, a PS como macropolítica e as ações do cotidiano, o discurso e a prática da PS, o que se busca problematizar por meio de reflexões e apontamentos baseados na literatura.

Há quase dez anos, Fernandez et al. (2008) já afirmavam que a discussão conceitual sobre a PS ainda estava em aberto, sob diferentes perspectivas, permanecia uma multiplicidade na qual a PS poderia significar uma promessa de mudança, por um lado, ou nada de novo, por outro, transitando desde processos educativos, produção e difusão da 'melhor' e mais 'clara' informação, empoderamento de indivíduos e comunidades, participação popular e a conquista da autonomia dos atores sociais, entre outros.

Da perspectiva deste estudo, problematizar a PS por meio da análise crítica de alguns temas torna-se importante para avançar na construção teórico-conceitual e dar elementos para a prática no SUS. A inovação que este ensaio enseja são as interpretações apresentadas que problematizam aquelas hegemônicas da PS, localiza-se no espaço do conhecimento nas lacunas encontradas nesta literatura que aparentemente cristalizaram alguns temas relacionados com a PS. Há na literatura, em geral, a ideia de que a PS e a prevenção de doenças são necessariamente antagônicas, contudo acredita-se que aquela é mais ampla do que esta, o que não a invalida.

Fruto de uma das etapas de construção de projeto de pesquisa, de caráter ensaístico, o texto foi construído a partir de revisão da literatura, buscando concepções mais abrangentes, sem a intenção de esgotar todas as possibilidades de análise sobre o tema. Esta análise buscou problematizar alguns porquês da PS, exprimindo-os, sem juízos de valor ou submissão à prova de fatos. Com isso, buscou-se proporcionar maior familiaridade com o problema, com vistas a construir diferentes interpretações daquelas hegemônicas (SILVEIRA; CÓRDOVA, 2009).

A pesquisa em bases de dados científicas que subsidiou o levantamento das referências, guiada por análise exploratória, ocorreu entre janeiro e novembro de 2016 por intermédio da Biblioteca Virtual em Saúde (BVS), da base de dados Scientific Electronic Library Online (SciELO) e sítios institucionais, principalmente do Ministério da Saúde (MS) utilizando o descritor: Promoção da Saúde. Expandiu-se ainda a análise com referências dos artigos recuperados na revisão e que possuíam relação com os temas abordados neste manuscrito. Também foram consideradas as vivências percepções e reflexões dos autores em espaços institucionais de gestão do SUS e da academia.

Na revisão citada, algumas questões importantes foram evidenciadas, em especial a quantidade de temas que podem ser relacionados com a PS, levantando a reflexão sobre como definir e operacionalizá-la. Nela, foi realizado um levantamento bibliográfico em meados de novembro de 2016 e foram encontrados no SciELO 765 artigos contendo o descritor: Promoção da Saúde. Após leitura do título e resumo, utilizando a primeira 
versão da Política Nacional de Promoção da Saúde (PNPS) que foi publicada em 2006 como marco político e histórico-temporal, foram selecionados 224 para leitura com o objetivo de avançar na discussão sobre a PS.

Em complemento, compartilha-se que, em outubro do mesmo ano, foram encontradas 3.379 dissertações e teses na Biblioteca Digital Brasileira de Teses e Dissertações do Instituto Brasileiro de Informação em Ciência e Tecnologia (BDTD/Ibict) ao incluir o descritor: Promoção da Saúde na opção pela pesquisa em todos os campos. Ora, dado o grande número de publicações sobre o tema, parece razoável afirmar que a PS é uma espécie de grande guarda-chuva no qual cabe toda sorte de temas relacionados com uma visão ampliada de saúde. Mais de 100 referências fizeram parte do projeto de pesquisa; a partir deles, foram feitos recortes e seleção para o objeto ora apresentado.

\section{Promoção da Saúde e prevenção de doenças}

Um resgate histórico contribui para a compreensão da PS, práticas que posteriormente poderiam ser denominadas como tal são datadas a partir do século XIX, por exemplo, com Virchow que já relacionava condições de saúde com condições de vida. Contudo, esta terminologia surgiu na década de 20 do século passado com Winslow e em $1945 \mathrm{com}$ Sigerist, como uma das tarefas essenciais da medicina, e no Modelo da História Natural das doenças de Leavell e Clark em 1958 (SOUZA; GRUNDY, 2004; WESTPHAL, 2006).

$\mathrm{Na}$ década de 1970, destacam-se o 'Informe Lalonde', que fomentou o questionamento do paradigma biomédico dominante, além da I Conferência Internacional sobre Cuidados Primários de Saúde, convocada pela Organização Mundial da Saúde realizada em Alma-Ata. Na década de 1980, destaca-se a 'Carta de Ottawa' que será abordada em seguida.
A partir de outra análise, a PS pode ser caracterizada por três momentos históricos: i) Início do século XIX até meados do século $X X$ - concepção higienista; ii) Segunda metade do século XX - enfoque na visão comportamentalista, prevalece o foco sobre os estilos e hábitos de vida e a responsabilização individual; iii) a partir de meados da década de 80 do século XX - concepção socioambientalista a partir das Conferências Internacionais, a PS como objeto de política pública, pressupondo a corresponsabilidade entre Estado e sociedade civil (SILVA ET AL., 2013). Destaca-se que as diferentes concepções de PS resistem e coexistem.

A partir desse resgate, apresentam-se três formas de conceituar a PS, cunhadas em momentos históricos e contextos nacionais diferentes: a da 'Carta de Ottawa', a da atual PNPS e do ‘Glossário temático’ da PS. É compreendida respectivamente como

processo de capacitação da comunidade para atuar na melhoria de sua qualidade de vida e saúde, incluindo uma maior participação no controle deste processo. (BRASIL, 2013, P. 20);

[...] um conjunto de estratégias e formas de produzir saúde, no âmbito individual e coletivo, caracterizando-se pela articulação e cooperação intra e intersetorial [...] buscando articular suas ações com as demais redes de proteção social, com ampla participação e controle social. (BRASIL, 2014, N. P.).

Ou ainda como

uma das estratégias de produção de saúde que, articulada às demais estratégias e políticas do SUS, contribui para a construção de ações transversais que possibilitem atender às necessidades sociais em saúde. (BRASIL, 2012, P. 29).

O primeiro conceito foi construído na I Conferência Internacional sobre Promoção da Saúde realizada em Ottawa no Canadá, que não teve participação de representantes 
brasileiros; o segundo é fruto do processo de revisão da PNPS que contou com participação da sociedade, controle social, gestores e especialistas (ROCHA ET AL,., 2014); e o terceiro é trabalho do MS, que teve aceitação por sua qualidade e clareza ao conceituar termos relacionados com a PS, extrapolando o objetivo inicial de padronizar a linguagem institucional.

Em comum entre eles: a saúde sendo produzida, ou seja, dinâmica, relacionada com o contexto sócio-histórico; a PS como um conjunto de estratégias que necessariamente deve ser articulada com outras para produzirem possíveis melhorias nas condições de vida, respondendo às necessidades sociais em saúde; a presença das dimensões individuais e coletiva/comunitária; a participação e controle social; e o destaque no setor saúde para liderar a intersetorialidade.

Para os objetivos deste ensaio, destacam-se os princípios e diretrizes da PS: concepção ampliada de saúde, participação social, intersetorialidade e intrassetorialidade, autonomia, equidade, empoderamento, a sustentabilidade, integralidade, territorialidade, sustentabilidade, protagonismo do sujeito e governança (BRASIL, 2013, 2014; WESTPHAL, 2006). Defende-se que não há obrigatoriedade de todos os princípios e diretrizes estarem presentes nas ações ou programas, nem há como pensar em um conjunto mínimo destes para que possa ser caracterizada a PS, defende-se que algum desses deve fazer parte dos objetivos, planejamento e execução das ações ou programas de PS e, a partir daí, buscar agregar outros.

Já a prevenção de doenças é definida como a tentativa de evitar o surgimento de doenças, reduzindo a incidência e prevalência nas populações. Baseia-se no controle da transmissão de doenças infecciosas e na redução do risco de doenças degenerativas e que geralmente a estratégia utilizada é a educação em saúde tradicional por meio da transmissão de informações com o objetivo de adoção de hábitos saudáveis e mudanças de comportamentos (SILVA ET AL., 2013).
Baseia-se na compreensão dos riscos ou da probabilidade de adoecimento, relacionando-a com a prevalência de doenças em determinada região e almejando evitá-las (SOUZA; GRUNDY, 2004). No enfoque da prevenção das doenças, o objetivo da atenção à saúde é evitar a doença ou enfermidade, ou seja, o indivíduo passa a ser o alvo da intervenção e é responsável pelo seu estado de saúde; atribui ao seu comportamento os fatores de risco para determinada doença. Assim, a prevenção de doenças é mais vinculada a uma visão biologicista e comportamentalista do processo saúde-doença, busca identificar riscos, atuar sobre eles, mas não considera a gênese desses riscos, sua natureza, mecanismos de atuação e a dimensão histórico-social do processo saúde-doença.

A PS, a partir da proposição de uma abordagem mais ampla, não só focada na doença, surgiu para preencher a lacuna que o modelo biomédico reducionista deixou. Para a PS, a prevenção e o tratamento das doenças, bem como a adoção de comportamento e estilo de vida saudável, requerem medidas de foro ambiental, econômico, sociocultural e legislativo para sua efetivação (sOUZA; GRUNDY, 2004). Para Silva (2008), a distinção entre a prevenção e a PS é a ênfase atribuída ao papel ativo das pessoas, grupos e organização no desenho das práticas e políticas de saúde.

Ou ainda, a PS é mais vinculada a uma visão holística e socioambiental desse processo, e suas diferenças e semelhanças com a prevenção de doenças são dadas a partir da relação com as concepções de saúde e a doença que orientam suas práticas e as vertentes político-ideológicas às quais se filiam (WESTPHAL, 2006). A PS implica um processo mais abrangente e contínuo, que envolve prevenção, educação e a participação de diferentes setores da sociedade na elaboração de estratégias que permitam a efetividade da educação para a saúde (CINCURÁ, 2014).

Assim, a PS não pode ser entendida apenas como um conjunto de procedimentos destinados a reduzir riscos de doenças 
(ROCHA; AKERMAN, 2014). Para Silva (2008), atuar na perspectiva da PS significa recuperar a saúde como prática socialmente construída e compreender que o êxito das mudanças pretendidas depende da participação e protagonismo da população e usuários, que deixam de ser reconhecidos como 'população-alvo' e passam a ser reconhecidos como sujeitos ativos e corresponsáveis.

A diferenciação entre uma ação de PS e outra ação que não pode ser caracterizada como tal está relacionada com o conceito de saúde das quais se originam, do alvo das ações e das abordagens utilizadas, ressaltando que tal diferenciação não é tão perceptível na prática e pouco se discute se ações ditas de PS estão incorporando seus princípios e diretrizes (CINCURÁ, 2014). Para Westphal (2006), a prevenção de doenças se aproximará da PS a partir da possibilidade de combinação de estratégias para que as ações também atuem sobre as causas dos problemas, e não só sobre riscos ou sinais e sintomas clínicos, assim como também contemplar o empoderamento individual e coletivo.

Para Karlsen e Villadsen (2016), a atual PS é menos uma questão de corrigir e normalizar os comportamentos do que incentivar comportamentos ou formas de andar a vida com prazer que permanecem dentro de certos limites sensíveis, por não serem nem puritanas nem fanáticas, nem se deslizarem para o que é considerado um comportamento puramente prejudicial à saúde.

Apresentadas as aproximações e distanciamentos entre a PS e a prevenção de doenças, Castiel, Guilam e Ferreira (2010) afirmam ainda ser necessário adotar postura vigilante acerca das diferentes roupagens que a PS pode assumir, já que há na literatura duas principais vertentes da PS: uma conservadora e outra crítica (CZERESNIA, 2003). Há denominações como visão comportamental; e voltada para enfrentamento da determinação social do processo saúde-doença (ROCHA ET AL., 2014), abordagens: biomédica, comportamental e socioambiental (WESTPHAL, 2006), as duas primeiras se aproximam da vertente conservadora, e a última, da crítica. Castiel, Guilam e Ferreira (2010) apontam uma terceira abordagem de PS sem aprofundar a análise desta.

Para Campos (2006), ainda há a permanência da lógica do pensar e agir em saúde que privilegia o enfoque dos efeitos nocivos de determinados comportamentos relacionados com o tabaco, com a atividade física e com a alimentação. Contudo, o autor afirma que também há a compreensão de que a saúde é vinculada à cidadania, autonomia na construção na forma de viver, logo comprometida com a equidade e a justiça social.

$\mathrm{Na}$ vertente conservadora, o objetivo principal é a mudança de comportamento para que sujeitos e coletividades tenham menos risco de adoecer. As estratégias utilizadas geralmente são enfocadas na possibilidade de a ação em favor da saúde ser baseada unicamente em sua vontade e esforço, desconsiderando o contexto. A literatura de governamentalidade que se concentrou nas questões de saúde tem prestado muita atenção às estratégias para inculcar a 'prudência', a 'autorresponsabilidade' ou o ‘cálculo do risco' (KARLSEN; VILLADSEN, 2016), o que parece permitir afirmar uma forte aproximação com a vertente conservadora.

Na vertente crítica, o objetivo principal é a transformação das condições de vida e saúde de indivíduos e coletivos; para isso, são utilizadas estratégias diversificadas, considera-se que há determinantes e condicionantes da saúde, que tornam mais ou menos factíveis a ação em favor da saúde individual e coletiva. Ao invés de inculcar a culpa interna como o motor para abandonar o comportamento insalubre, é por meio do exercício de práticas e aquisição de novos gostos que uma mudança de modos de vida saudável terá lugar (KARLSEN; VILLADSEN, 2016).

Assim, a prevenção de doenças e a vertente conservadora da PS estariam mais relacionadas com a mudança de hábitos de vida e comportamentos baseados na prescrição e disponibilização de informações de forma 
descontextualizada. A informação é importante e necessária, mas não é suficiente, é preciso investigar e agir sobre as possibilidades e interesses dos sujeitos e coletividades em efetivar o que é informado ou prescrito, seja por serviços e profissionais de saúde, seja pela mídia leiga ou especializada. É comum que ocorra a culpabilização daqueles que não adotam as recomendações, desconsiderando que muitas vezes as causas estão interligadas a dimensões sociais, econômicas, culturais que estão fora da governabilidade individual.

Mássimo e Freitas (2014) destacam que frequentemente as ações e programas de saúde centrados em comportamentos fracassam porque buscam convencer sujeitos a modificá-los, a partir da consideração de que seriam prejudiciais ou arriscados à saúde e à vida, acreditando-se que a informação está no centro, quando ela é somente parte de um processo para reconstruir representações, em meio à subjetividade e uma racionalidade limitada quando se trata de riscos, especialmente de riscos em saúde.

Karlsen e Villadsen (2016) abordam a ênfase analítica no papel do prazer ou divertimento nas atuais campanhas de saúde, em um determinado contexto, no qual há o desafio às interpretações que enfatizam univocamente as demandas de cálculo racional do risco, apelo à abstenção e à supressão dos prazeres irracionais. De fato, a PS contemporânea parece ter incorporado certos incentivos ao prazer, divertimento ou mesmo transgressão.

Mássimo e Freitas (2014), em complemento, afirmam, baseadas nas reflexões dos grupos participantes de sua pesquisa, a existência de representações centradas na impossibilidade de considerar a saúde em primeiro plano e, constantemente, na vida cotidiana devido à existência de desejo de viver prazeres e satisfações, que, muitas vezes, não são coerentes com a determinação de ser saudável. Além disso, as autoras lembram que há a necessidade humana de transgressões para se sentir vivo e mais forte que a morte.

Destaca-se até aqui que a PS necessita dialogar não só com a racionalidade científica, mas também com a subjetividade dos desejos, histórias e contextos de vida para tornar mais factível produzir saúde. Além de, na relação entre a PS e a prevenção de doenças, a utilização de termos como: centrados; focados; mais amplos; mais abrangentes; ênfase/enfatizar; ou ainda, em contraste: limitados; entre outros, que são utilizados para demarcar a superação da prevenção de doenças pela PS, mas que evidenciam a relação entre elas.

\section{A Promoção da Saúde na Atenção Básica}

De forma sucinta, alguns apontamentos sobre a PS e a prevenção de doenças nos serviços de saúde, em especial da $\mathrm{AB}$, contribuem para o debate realizado neste ensaio já que há a crença de que a PS está no cotidiano dos serviços de saúde, não só na $\mathrm{AB}$, mas também de uma forma apriorística, ou seja, algumas ações são classificadas como tal sem que necessariamente tenham seus princípios e diretrizes em seu escopo, operacionalização e objetivos.

As ações que figuram na primeira versão da PNPS e que foram mantidas na atual versão, como a atividade física ou a alimentação saudável, são exemplos, ou ainda as atividades coletivas, de educação em saúde, independentemente do tema ou da forma de abordagem. Optou-se por apresentar a PS na $\mathrm{AB}$ por ser um campo no qual classicamente ela e a prevenção de doenças possuem 'fronteiras' muito próximas.

A porta de entrada da PS no SUS foi a Estratégia Saúde da Família (ESF), e há o reconhecimento da relevância da $\mathrm{AB}$ e da ESF para sua implementação (ROCHA ET AL., 2014), para Silva e Rodrigues (2010), a ESF configura-se como espaço privilegiado para o desenvolvimento de práticas promotoras de saúde por ser uma estratégia destinada a reorientar o modelo assistencial por meio da prestação de serviços e ações de saúde pautada nos 
princípios da universalidade, equidade, integralidade e participação social.

Contudo, ainda que haja um aparente consenso em torno da ideia de incorporação da PS no âmbito das políticas, a forma como isso se traduz em operações concretas no âmbito das práticas de saúde é bastante diversa (MEDINA ET AL., 2014). Muitos estudos que abordam experiências de implementação de ações de PS trazem discursos relacionados com os princípios, todavia sem avaliar as ações desenvolvidas (CINCURÁ, 2014), assim não seria possível afirmar que atenderam aos princípios e diretrizes da PS.

Afirma-se que os processos de trabalho na ESF ainda se orientam fortemente pelo enfoque centrado na doença, na cura e nos indivíduos baseados em um modelo de saúde médico-centrado, especializado (ROCHA; AKERMAN, 2014); e a maioria do cuidado em saúde ofertado é limitada à abordagem de fator de risco, centrado em ações programáticas e pontuais (TEIXEIRA ET AL., 2014). As ações de PS analisadas ainda são incipientes e possuem baixa institucionalização no âmbito da ESF (MEDINA ET AL., 2014).

Teixeira et al. (2014) afirmam que as práticas de PS são fragmentadas e focalizadas e que é necessária a integração entre cuidado clínico, prevenção e PS. Na realidade pesquisada, as práticas relacionadas com a prevenção de doenças estavam centradas na atenção a grupos de risco biológico, eram organizadas em pacotes e turnos fechados, tinham como objetivo o manejo clínico e a prevenção relacionados, estritamente, com o estilo de vida, ou seja, um modelo preventivo de educação em saúde muito pouco efetivo.

\section{Refletindo sobre o instituído na Promoção da Saúde}

Ao revisitar a distinção entre PS e prevenção de doenças, em especial ao objetivar problematizar que aquela contribui para que doenças sejam prevenidas, mas não se esgota aí, é importante debater algumas questões caras à PS. Essa distinção citada e aquela entre as vertentes apresentadas revelam alguns 'dogmas' da PS, ou seja, uma defesa de que algumas estratégias, a priori, não poderiam ser relacionadas com a vertente crítica.

Inicia-se destacando que a ideia de 'mudança de comportamento' geralmente não é considerada na vertente crítica da PS, apesar de algumas condições de saúde, em geral, terem como oferta de cuidado para prevenção e tratamento tais mudanças. A vertente conservadora da PS não se caracterizará se as mudanças não forem baseadas na ideia de que o sujeito possui total governabilidade para realizar as medidas terapêuticas necessárias e não as faz simplesmente porque não quer ou por não possuir 'força de vontade', mas na construção de possibilidades por meio do empoderamento deste sujeito.

Destaca-se o surgimento de um objetivo reconfigurado da PS que não envolve uma 'conversão' do indivíduo em um discípulo de salubridade, o problema muda de ser a falta de autodomínio e passa a ser um problema de equilíbrio entre autocontrole e desejo, racionalidade e prazer. Assim, uma PS 'desejável' deve tomar como ponto de partida o reconhecimento não apenas de liberdade pessoal e informada, mas também de desejos conflitantes (KARLSEN; VILLADSEN, 2016).

Logo, a mudança de comportamento se dará por meio do aumento da autonomia, assim buscar-se-á alcançar maior participação e envolvimento de sujeitos e coletivos com as decisões relacionadas com a saúde, entre outras. A construção dessas possibilidades, na relação entre sujeitos e trabalhadores e serviços de saúde, relaciona-se com a negociação e conquista, com o poder compartilhado, com saberes distintos, mas igualmente importantes.

O pressuposto parece ser que o sujeito alvo da proposta de mudança de comportamento está fundamentalmente dividido entre duas disposições: por um lado, é suscetível de apelos 
por comportamentos de saúde prudentes e racionais, por outro, há desejo e prazer, uma irracional resistência a esses recursos. Aqui, o objetivo da PS é de promover um sujeito que seja capaz de equilibrar o cuidado de sua saúde (KARLSEN; VILLADSEN, 2016), com o apoio dos serviços e profissionais de saúde, com seus prazeres, desejos e possibilidades dado o contexto no qual está inserido.

Diferentes ciclos de vida, segundo Mássimo e Freitas (2014), possuem diferentes representações sobre formas de lidar com a saúde, denotando alguma necessidade de transgressão ou desejo de viver prazeres e aventuras e a impossibilidade de pensar em saúde constantemente no cotidiano, o que se opõe, fundamentalmente, ao modelo prescritivo das ações de saúde ainda existente.

Assim, as mudanças comportamentais podem ser necessárias, porém, a questão é a forma como elas serão construídas na relação entre os sujeitos, trabalhadores e serviços de saúde. É necessário desconstruir a conotação negativa apriorística da mudança de comportamento, a partir da defesa desta absolutamente pactuada com os sujeitos e associada à busca de mudanças no contexto no qual os sujeitos e coletividades estão inseridos. A ênfase se dirige às formas complexas de interação entre comportamento individual e coletivo; e conjunto de recursos existentes nas comunidades (CASTIEL; GUILAM; FERREIRA, 2010).

É comum, na abordagem da vertente crítica de PS, em oposição à terminologia e ideia relacionadas à mudança de comportamento, a utilização do termo/conceito: construção de modos de vida saudável. Os modos de vida são a instância determinante dos processos saúde-enfermidade, mediada pelas dimensões estilo de vida e condições de vida, aquele relacionado com formas sociais e culturalmente determinadas de viver, que se expressa em condutas e está relacionada com as condições materiais necessárias à subsistência (FIGUEIRA ET AL., 2015).

Destaca-se a necessidade e importância de superar: propostas conservadoras relacionadas com o estilo de vida, o foco no comportamento individual a partir da consideração de que aspectos sociais, culturais e materiais condicionam as formas de viver. Tais fatores devem ser considerados na construção das possibilidades de mudança de comportamento, assim, tal mudança é compreendida neste ensaio como parte de um processo mais amplo, que supera a culpabilização e reconhece a necessidade de atuação sobre o contexto no qual está inserido o sujeito.

Em complemento, aborda-se a PS e a sua distinção como discurso e como prática cotidiana nos serviços de saúde. No primeiro caso, há a relação entre ela e as condições de vida de sujeitos e coletividades, contudo, tal relação, em geral, fica apenas no âmbito idealístico, assim são estabelecidas condições para que uma ação ou programa seja considerado de PS, por exemplo: necessariamente tem que ocorrer a intersetorialidade e empoderamento e participação social e outros, além de ter que cursar necessariamente com mudanças macro nas condições de vida.

Se não houver, simultaneamente, esses e outros princípios e diretrizes da PS, não pode ser considerado como tal, o que inviabilizaria, a rigor, que um serviço de saúde ou locais que utilizem o esporte e lazer, a geração de emprego e renda etc., como ferramentas, atuassem com a PS.

Defende-se que é possível que programas ou ações de PS iniciem com ações individuais de trabalhadores ou de apenas um serviço de saúde e, a partir do êxito, vão ganhando visibilidade, agregando parceiros e capital político para buscar contemplar e agregar mais princípios e diretrizes da PS. Logo, é necessário relativizar a necessidade dos programas e ações conterem, em todos os momentos, diversos princípios e diretrizes da PS, conforme já discutido.

Assim como considerar que as mudanças nas condições de vida são processuais e podem significar pequenas conquistas para os sujeitos, relacionadas, por exemplo, com a dimensão da vida cotidiana como outra forma de compreender e encarar o contexto na qual está inserido, mesmo com suas adversidades e 
complexidades, a partir do aumento da autonomia e empoderamento. Mássimo e Freitas (2014) afirmam que a adesão a modos de vida saudáveis é uma construção social dependente, entre outros fatores, das representações sobre risco em saúde, compreendidas nas trajetórias de vida porque os sujeitos acumulam uma bagagem psicossocial, pelas vivências e interações, que se renova e se reconstrói.

Outro ponto relacionado com a PS a ser discutido sucintamente é a possibilidade de atuação no âmbito individual. Em geral, há o entendimento de que isso não caracterizaria a PS, apesar de a dimensão individual estar presente nos diferentes conceitos de PS apresentados anteriormente. A atuação citada é também necessária, contudo é importante não haver a descontextualização das questões que envolvem sua condição de saúde, que fogem ao âmbito individual.

O objetivo é o aumento da autonomia do sujeito, tratando-se da consideração de que o aumento das opções para o cuidado individual e coletivo da saúde relaciona-se com mudanças nas condições e no contexto de vida. Por meio do modelo de determinação social da saúde, é possível visualizar que os fatores determinantes da saúde estão dispostos no âmbito pessoal, além do comunitário e estrutural. Isso reforça a necessidade de atuação, em ações de PS, também no âmbito pessoal já que as ações apresentam diferentes possibilidades de atuação nos três âmbitos citados (CINCURÁ, 2014).

Os comportamentos individuais, modos de vida ou fatores de risco precisam ser problematizados, há a necessidade de estratégias e intervenções nos âmbitos individuais e coletivos com o reconhecimento da dificuldade de mudanças nos comportamentos individuais e nos modos de vida, de trabalho e de lazer, sem que se ocorram mudanças no contexto (SILVA, 2008).

É importante destacar que há o afastamento da perspectiva defendida sobre a abordagem individual na PS quando ocorre a responsabilização exclusiva do comportamento individual, desconsiderando os fatores sociais, econômicos, culturais, entre outros, a partir da crença de que mudanças são de plena governabilidade dos sujeitos e coletividades, o que Verdi e Caponi (2005) denominaram como hipertrofia do campo de ação da PS conhecido como o desenvolvimento de habilidades individuais. A PS combina escolhas individuais com a responsabilidade social pela saúde mediante a participação da população.

Dessa forma, longe de afastar o âmbito individual, a PS precisa considerá-los, necessita avançar em estratégias de comunicação e negociação para que seja factível o alcance de gradações crescentes de saúde individual e também coletiva. Ressalta-se a valorização e escuta das trajetórias, narrativas e histórias de vida dos sujeitos buscando produzir cuidado a partir destas singularidades (ROCHA; AKERMAN, 2014).

Assim, a atuação no âmbito individual considera que questões estruturais e contextuais condicionam, em maior ou menor grau, a forma como se relaciona com a saúde, ou seja, sujeitos e coletividades não possuem governabilidade ampla e irrestrita para mudar seus comportamentos mesmo que concordem e desejem isso. As informações e recomendações são ressignificadas a partir da interação com os sujeitos, seus saberes, crenças, valores e desejos.

Por último, a PS é abordada como macropolítica ou como embasamento para programas e ações de saúde, sem que haja interação com a atuação no cotidiano. A distinção entre PS como macropolítica e como ferramenta no cotidiano dos serviços de saúde pode ser exemplificada por meio da adesão do Brasil à Convenção Quadro para o Tabaco da Organização Mundial da Saúde (CQCT/OMS). Esta possui o objetivo de proteger sujeitos e coletividades das consequências sanitárias, sociais, ambientais e econômicas geradas pelo tabaco. Em 2013, o Programa Nacional de Controle do Tabagismo (PNCT) para equipes da $\mathrm{AB}$ teve a adesão por meio do $2^{\mathrm{o}}$ ciclo do Programa Nacional de Melhoria do Acesso e da Qualidade na Atenção Básica (PMAQ-AB).

A adesão ao CQCT consiste, na leitura 
que está sendo problematizada, em uma macropolítica de PS, já o tratamento ofertado na $A B$ consiste na clínica ou na prevenção e tratamento, ou seja, não seria PS. A dimensão da atenção à saúde na PS é outro tema que geralmente não é abordado nas discussões conceituais e práticas, contudo não será abordada neste ensaio. Destaca-se a armadilha de distanciar a PS da clínica (CAMPOS, 2006), é necessário agregar a PS, prevenção de doenças, a terapêutica e a clínica.

Assim, neste tópico, discutiu-se o que se está denominando como o instituído na PS, na perspectiva de problematizar e avançar na construção teórico-conceitual da PS, em especial da sua vertente crítica.

\section{Considerações}

Na parte final deste ensaio, defende-se que, ao considerar que sujeitos e coletividades são parte de um contexto, de uma sociedade e que isso está relacionado com a forma como eles cuidam da saúde, mais ou menos próximos das recomendações 'científicas', as práticas de PS buscam também prevenir doenças e/ou atenuá-las. Para isso, em sua vertente crítica, busca utilizar como estratégia não a mera prescrição de comportamentos saudáveis, mas a construção de possibilidades, que pode envolver também mudanças de comportamento, que são negociadas e pactuadas entre os sujeitos, profissionais, trabalhadores e serviços de saúde.

A problematização do fato de a PS ser, muitas vezes, classificada aprioristicamente, ou seja, acreditar-se que determinadas temáticas e ações são de PS sem analisar a forma como são efetivadas contribui para preencher lacunas que a vertente crítica da PS apresenta. Multiestratégica, interdisciplinar e com ações abrangentes, a PS na formação dos profissionais de saúde e na prática cotidiana dos serviços de saúde é uma importante forma de produzir saúde a partir, entre outras coisas, da construção de projetos terapêuticos em conjunto com os beneficiários. Logo, devem ter sua história de vida, seus desejos e crenças respeitados, também deve ser considerado o contexto no qual vivem, além do saber técnico-científico dos profissionais e trabalhadores da saúde.

Buscou-se neste ensaio relativizar a diferenciação com o conceito de prevenção de doenças a partir da compreensão de que a PS é mais ampla e complexa do que aquela. Além de abordar de forma crítica o discurso e a prática da PS, a mudança de comportamento, as estratégias individuais, a PS como macropolítica e as ações do cotidiano.

A PS está relacionada com a autonomia e empoderamento individuais e coletivos, com a participação para transformar e melhorar as condições de vida e saúde, incluindo aí as ações cotidianas nos serviços de saúde, no espaço micropolítico da vida de sujeitos e coletividades, mas que não se restringem ao foco individual e culpabilizador baseada na comunicação autoritária que só considera o saber técnico-científico.

Retoma-se aqui a ideia de negociação como uma importante forma de consolidar a PS, ressaltando os princípios e diretrizes relacionados com a integralidade, participação social, equidade e protagonismo do sujeito, pois a tornam também uma forma de prevenir doenças por meio de melhores condições de vida e de saúde, que incluem melhoras de marcadores biológicos de saúde, mas não se esgotam neles, ou seja, a PS busca melhorias em todas as dimensões da vida, considerando desde as melhorias micro relacionadas com o cotidiano até as macropolíticas.

\section{Colaboradores}

Fabio F. B. de Carvalho: concepção, delineamento, análise e interpretação dos dados e informações; redação do artigo e aprovação da versão a ser publicada.

Simone C. Cohen: concepção, revisão crítica e aprovação da versão a ser publicada.

Marco Akerman: revisão crítica e aprovação da versão a ser publicada. 


\section{Referências}

BRASIL. Ministério da Saúde. Portaria GM/MS No

2.446, de 11 de novembro de 2014. Redefine a Política

Nacional de Promoção da Saúde. Diário Oficial [da]

República Federativa do Brasil, Brasília, DF, 11 nov. 2014.

Disponível em: <http://bvsms.saude.gov.br/bvs/saude-

legis/gm/2014/prt2446_11_11_2014.html>. Acesso em:

17 jul. 2016

Ministério da Saúde. Secretaria Executiva.

Secretaria de Vigilância em Saúde. Glossário temático: promoção da saúde. Brasília, DF: Ministério da Saúde, 2012 .

Ministério da Saúde. Secretaria de Vigilância em Saúde. Curso de extensão em promoção da saúde para gestores do SUS com enfoque no Programa Academia da Saúde. Brasília, DF: Ministério da Saúde, 2013.

CAMPOS, G. W. S. Prefácio. In: CASTRO, A.; MALO, M. (Ed.). SUS: ressignificando a promoção da saúde. São Paulo: Hucitec; 2006. p. 11-12.

CASTIEL, L. D.; GUILAM, M. C. R.; FERREIRA, M. S Correndo o risco: uma introdução aos riscos em saúde. Rio de Janeiro: Fiocruz, 2010.

CINCURÁ, R. N. S. Promoção da saúde na atenção primária: proposição de um modelo e sua aplicação na análise de ações desenvolvidas no Brasil. 2014. 78 f. Dissertação (Mestrado em Saúde Comunitária) Instituto de Saúde Coletiva, Universidade Federal da Bahia, Salvador, 2014. Disponível em: <https:// repositorio.ufba.br/ri/bitstream/ri/16407/1/DISS\%20 Rosana\%20Cincur\%C3\%A1.\%202014.pdf>. Acesso em: 17 jul. 2016.

CZERESNIA, D. O conceito de saúde e a diferença entre prevenção e promoção. In: CZERESNIA, D. FREITAS, C. M. (Org.). Promoção da saúde: conceitos, reflexões, tendências. Rio de Janeiro: Fiocruz, 2003. p. $39-53$.

FERNANDEZ, J. A. et al. Promoção da Saúde: elemento instituinte? Saúde e Sociedade, São Paulo, v. 17, n. 1, p. 153-164, 2008. Disponível em: < http://www.
producao.usp.br/bitstream/handle/BDPI/12871/art PELICIONI_Promocao_da_saude_elemento_instituinte_2008.pdf?sequence=1>. Acesso em: 17 jul. 2016.

FIGUEIRA, T. R. et al. Percepções sobre adoção e aconselhamento de modos de vida saudáveis por profissionais de saúde. Trabalho, Educação e saúde, Rio de Janeiro, v. 13, n. 1, p. 181-200, jan./abr. 2009. Disponível em: <http://www.scielo.br/scielo.php?script=sci abstract\&pid=S1981-77462015000100181\&lng=pt\&nrm= iso>. Acesso em: 17 jul. 2016.

KARLSEN, M. P.; VILLADSEN, K. Health Promotion, Governmentality and the Challenges of Theorizing Pleasure and Desire. Body \& Society. Thousand Oaks, v. 22, n. 3, p. 3-30, set. 2016.

Disponível em: <http://journals.sagepub.com/doi/ abs/10.1177/1357034X15616465\#>. Acesso em: 17 jul. 2016.

MÁSSIMO, L. E. A.; FREITAS, M. I. F. Riscos para doenças crônicas não transmissíveis na ótica de participantes do Vigitel. Saúde e Sociedade, São Paulo, v. 23, n. 2, p. 651-663, 2014. Disponível em: <http://www.scielo. br/pdf/sausoc/v23n2/0104-1290-sausoc-23-2-0651. pdf>. Acesso em: 17 jul. 2017.

MEDINA, M. G. et al. Promoção da saúde e prevenção de doenças crônicas: o que fazem as equipes de Saúde da Família? Saúde em Debate, Rio de Janeiro, v. 38, n. esp. p. 69-82, out. 2014. Disponível em: <http:// www.scielo.br/pdf/sdeb/v38nspe/0103-1104-sdeb-38spe-0069.pdf>. Acesso em: 17 jul. 2016.

ROCHA, D. G.; AKERMAN, M. Determinação Social da Saúde e Promoção da Saúde: isto faz algum sentido para a Estratégia de Saúde da Família? Em que sentido podemos seguir? In: SOUZA, M. F.; FRANCO, M. S.; MENDONÇA, A. V. M. (Org.). Saúde da família nos municípios brasileiros: os reflexos dos 20 anos do espelho do futuro. Campinas: Saberes, 2014, p. 720-754.

ROCHA, D. G. et al. Processo de revisão da Política Nacional de Promoção da Saúde: múltiplos movimentos simultâneos. Ciência \& Saúde Coletiva, Rio de 
Janeiro, v. 19, n. 11, p. 4313-4322, 2014. Disponível em: <http://www.scielo.br/pdf/sdeb/v38nspe/0103-1104sdeb-38-spe-0069.pdf >. Acesso em: 17 jul. 2016.

SILVA, C. M. Equidade e promoção da saúde na estratégia Saúde da Família: desafios a serem enfrentados. Revista de Atenção Primária à Saúde, Juiz de Fora, v. 11, n. 4, p. 451-458, out./dez. 2008.

SILVA, K. L.; RODRIGUES. A. T. Ações intersetoriais para promoção da saúde na Estratégia Saúde da Família: experiências, desafios e possibilidades. Revista Brasileira de Enfermagem, Brasília, DF, v. 63, n. 5, p.7629, set-out 2010.

SILVA, K. L. et al. Promoção da saúde e intersetorialidade em um município da região metropolitana de Belo Horizonte/MG. Revista de Atenção Primária à Saúde, Juiz de Fora, v. 16, n. 2, p. 165-172, abr./jun. 2013.

SILVEIRA, D. T.; CÓRDOVA, F. P. A pesquisa científica In: GERHARDT, T. E.; SILVEIRA, D. T. (Org.). Métodos de pesquisa. Porto Alegre: UFRGS, 2009. p. 31-42.

SOUZA, E. M.; GRUNDY, E. Promoção da saúde, epidemiologia social e capital social: inter-relações e perspectivas para a saúde pública. Cadernos de Saúde Pública, Rio de Janeiro, v. 20, n. 5, p. 13541360, set./out. 2004. Disponível em: <http://www.
scielo.br/scielo.php?script=sci_arttext\&pid=S0102-311X2004000500030>. Acesso em: 7 jul. 2016.

TEIXEIRA, M. B. et al. Avaliação das práticas de promoção da saúde: um olhar das equipes participantes do Programa Nacional de Melhoria do Acesso e da Qualidade da Atenção Básica. Saúde em Debate, Rio de Janeiro, v. 38, n. esp. p. 52-68, out. 2014. Disponível em: $<$ http://www.scielo.br/pdf/sdeb/v38nspe/0103-1104sdeb-38-spe-0052.pdf $>$. Acesso em: 17 jul. 2016.

VERDI, M.; CAPONI, S. Reflexões sobre a promoção da saúde numa perspectiva bioética. Texto \&t Contexto Enfermagem, Florianópolis, v. 14, n. 1, p. 82-8, jan./mar. 2005. Disponível em: <http://www.scielo.br/pdf/tce/ vl4nl/allvl4nl>. Acesso em: 17 jul. 2016.

WESTPHAL, M. F. Promoção da saúde e prevenção de doenças. In: CAMPOS, G. W. S. et al. (Org.). Tratado de saúde coletiva. São Paulo: Hucitec; Rio de Janeiro: Fiocruz, 2006. p. 635-667.

Recebido para publicação em janeiro de 2017 Versão final em junho de 2017

Conflito de interesses: inexistente Suporte financeiro: não houve 